\title{
OPTIMALIZATION OF SINTERING CONDITIONS FOR TUNGSTEN HEAVY ALLOY
}

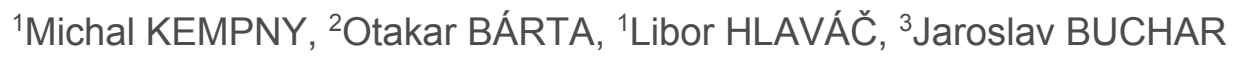 \\ ${ }^{1}$ VSB - Technical University of Ostrava, Ostrava, Czech Republic, EU \\ michal.kempny.st@vsb.cz \\ 2UJP PRAHA, a. s., Praha, Czech Republic, EU \\ ${ }^{3}$ Institute of Thermomechanics, Czech Academy of Sciences, Czech Republic, EU
}

https://doi.org/10.37904/metal.2019.750

\begin{abstract}
The influence of different sintering conditions (sintering temperature and time) on the structure and properties of the investigated tungsten heavy alloy (THA) consisting of tungsten, cobalt, and nickel was evaluated within this study. The samples for sintering were prepared by powder metallurgy techniques (powder mixing followed by isostatic compression), the microstructures were investigated via optical and scanning electron microscopy, and the mechanical properties were investigated by tensile testing. The first part of the experiment was focused on finding the critical temperature to acquire the required microstructure, while the second part was focused on comparison of two selected sintering periods in order to acquire the best possible combination of mechanical and structure properties. The highest hardness reached up to $500 \mathrm{HV}$ for the sample sintered at $1500^{\circ} \mathrm{C}$, however, increasing the sintering temperature to $1525^{\circ} \mathrm{C}$ even increased the ultimate tensile strength which exceeded $1000 \mathrm{MPa}$. This sample also consisted of the smallest agglomerates.
\end{abstract}

Keywords: Tungsten heavy alloy; powder metallurgy; sintering; scanning electron microscopy

\section{INTRODUCTION}

Due to their favourable properties, tungsten heavy alloys (THA) are applicable within a variety of technical and industrial branches [1]. They can advantageously be used for military applications, such as kinetic penetrators, or as replacement of highly toxic depleted uranium [2]. THAs are also used as radiation shielding in medicine, or mass balances in aeronautics $[3,4]$.

Fabrication of THAs is usually performed via powder metallurgy techniques, which are advantageous for preparation of various kinds of materials, in combination with severe plastic deformation technologies, such as equal channel angular pressing and its modifications, even for preparation of ultra-fine grained (UFG) materials. The powder mixtures typically consist of tungsten (forming majority of the mixture, usually $>90 \mathrm{wt} \%$ ) plus other elements such as $\mathrm{Co}, \mathrm{Ni}, \mathrm{Cu}$, or $\mathrm{Fe}$ [5]. The THAs production chain typically involves powders mixing, isostatic compression, sintering and final tempering [6]. Based on works by others, e.g. Chun-Liang Chen and Shih-Sun Ma [7], the final microstructures after sintering are compact and without pores and consist of tungsten agglomerates surrounded by matrix formed by the other elements, e.g. cobalt and nickel. The processing conditions during these procedural steps, together with the individual chemical composition, provide the sintered material with the final structure and mechanical properties. For example, Bose and German [8] reached the tensile strength of $903-986 \mathrm{MPa}$ and elongation of about $30 \%$ after sintering in vacuum at the maximum temperature of $1500{ }^{\circ} \mathrm{C}$ with $30 \mathrm{~min}$ time dwell.

This paper is focused on optimizing the sintering procedure, i.e. the combination of optimum sintering temperature and time period. The main aim was to achieve the size of tungsten agglomerates between 20 $30 \mu \mathrm{m}$, according to UJP a. s. company requirements. Among the interests of the experiments was also the achievement of the best possible structure and mechanical properties and reduction of final ovality of the sintered rods introduced by melting of the matrix during sintering. 


\section{EXPERIMENTAL WORKS}

Within the first part of the study, the optimal temperature was investigated. For this experiment, we prepared five pre-compacted rods of the approximate length of $100 \mathrm{~mm}$, which were subsequently sintered at different temperatures. The scale of the used temperatures varied within $1450-1550{ }^{\circ} \mathrm{C}$ (Table 1). The goal was to find the minimal sintering temperature ensuring the achievement of the desired microstructure and, at the same time, preventing ovality of the sintered rods, which can develop during the phase transformation of low melting temperature elements ( $\mathrm{Co}$ and $\mathrm{Ni}$ ) in the matrix to liquid phase. Based on the previous experience of the UJP company, the selected sintering time for the first experiments was 20 minutes.

Table 1 Maximum sintering temperatures

\begin{tabular}{|l|l|l|l|l|l|l|}
\hline Temperature & $\left({ }^{\circ} \mathrm{C}\right)$ & 1450 & 1475 & 1500 & 1525 & 1550 \\
\hline
\end{tabular}

After finding the optimum temperature $\left(1525^{\circ} \mathrm{C}\right.$, see results and discussion section), the second part was focused on the investigation of how a longer time dwell $(180 \mathrm{~min})$ at the maximum temperature affects the microstructure and agglomerate and grain size. The samples were thus sintered for the time periods of 20 and 180 minutes (Table 2).

Table 2 Time periods used for different sintering temperatures

\begin{tabular}{|c|c|c|c|c|c|c|}
\hline Time & $(\mathrm{min})$ & 20 & 180 & 20 & 180 & 20 \\
\hline Temperature & $\left({ }^{\circ} \mathrm{C}\right)$ & 1500 & 1500 & 1525 & 1525 & 1550 \\
\hline
\end{tabular}

Within this experimental stage, the final grain sizes of all the samples were compared in order to select the most favourable processing conditions with respect to the Hall-Patch relation [9]. Samples for metallographic analyses were cut by water jet cutter to avoid any possible effect of locally increased temperature during conventional cutting on the structure. The cut samples were then investigated by optical microscopy using an Olympus device, and via scanning electron microscopy (SEM) using Tescan Lyra 3 FIB/SEM microscope equipped with a NordlysNano EBSD detector and EDX detector. The SEM was also used to perform analyses of chemical compositions via the energy dispersive spectroscopy (EDX) method. All the samples were also tested by tensile testing and microhardness measurements. The conditions for the tensile tests were the following: sample diameter $\left(d_{0}-5 \mathrm{~mm}\right)$, sample length $\left(L_{0}-25 \mathrm{~mm}\right)$. The load for microhardness testing was $200 \mathrm{~g}$ and the load time was $15 \mathrm{~s}$.

\section{$3 \quad$ RESULTS AND DISCUSION}

The pre-compacted samples, the example of which is shown in Figure 1a, intended for subsequent sintering were prepared by isostatic compression in UJP - Praha, a.s. company. The chemical composition of the investigated THA determined via SEM-EDX is shown in Figure $\mathbf{1 b .}$

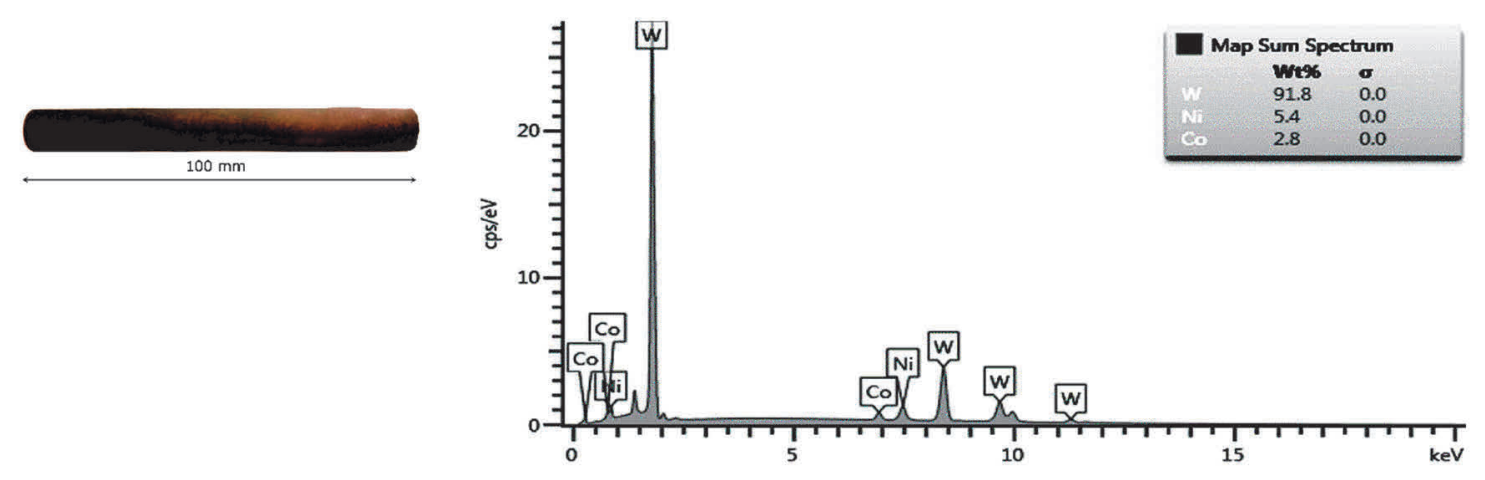

Figure 1 Pre-compacted sample and chemical composition 
The first experiment showed that the critical temperature the tungsten grains at which cluster to globular agglomerates is around $1500{ }^{\circ} \mathrm{C}$. At temperatures equal and lower than $1475^{\circ} \mathrm{C}$, tungsten within the structure was in the form of grains. Figure $2 \mathrm{a}$ shows an example of the structure for the sample sintered at $1475{ }^{\circ} \mathrm{C}$ for 20 minutes. In the figure, grain boundaries are highlighted by bold lines. As can be seen in Figure $\mathbf{2 b}$, the sintering temperature of $1500{ }^{\circ} \mathrm{C}$ exhibited favourable structural properties. Grain size critically increased with increasing temperature, as shown in Figure $\mathbf{2 c}$.
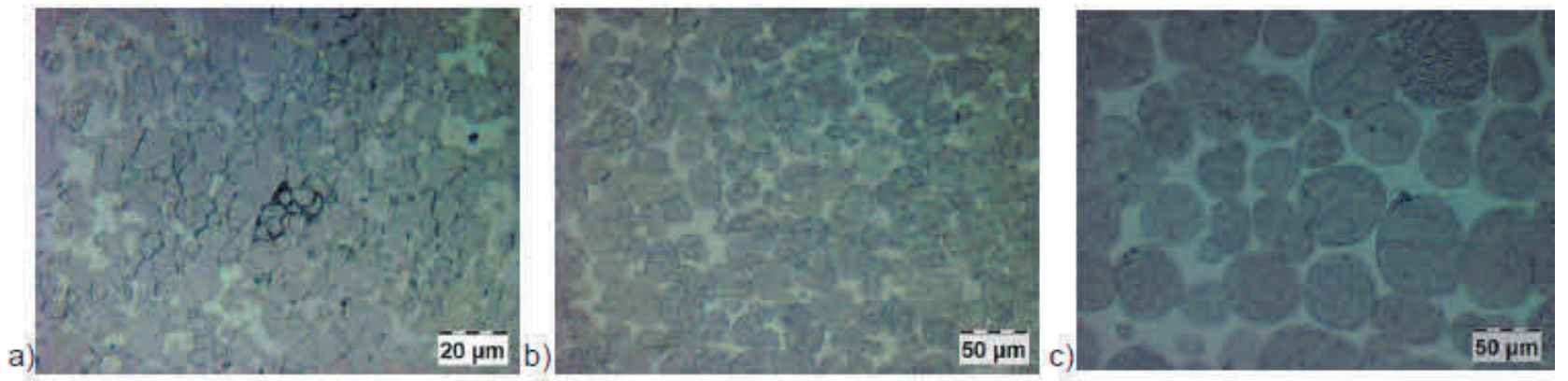

Figure 2 Structures acquired by optical microscopy; $1475{ }^{\circ} \mathrm{C}(\mathrm{a}), 1500{ }^{\circ} \mathrm{C}(\mathrm{b}), 1550{ }^{\circ} \mathrm{C}(\mathrm{c})$

The temperature of $1500{ }^{\circ} \mathrm{C}$ was critical for formation of the desired microstructure; at temperatures above 1 $500{ }^{\circ} \mathrm{C}$, the structures were formed by tungsten agglomerates surrounded with matrix. The grain size increased with increasing temperature. The prolongation of sintering time affected positively microstructure formation (due to e.g. supported diffusion), however, negatively the mechanical properties (i.e. decreased strength). The THA sintered at the temperature of $1500{ }^{\circ} \mathrm{C}$ featured low ductility $(4 \%)$, but the diffusion contributed to formation of agglomerates. At the temperature of $1500{ }^{\circ} \mathrm{C}$ the desired structure after sintering was not fully formed and contained pores (Figure 2a).

a)

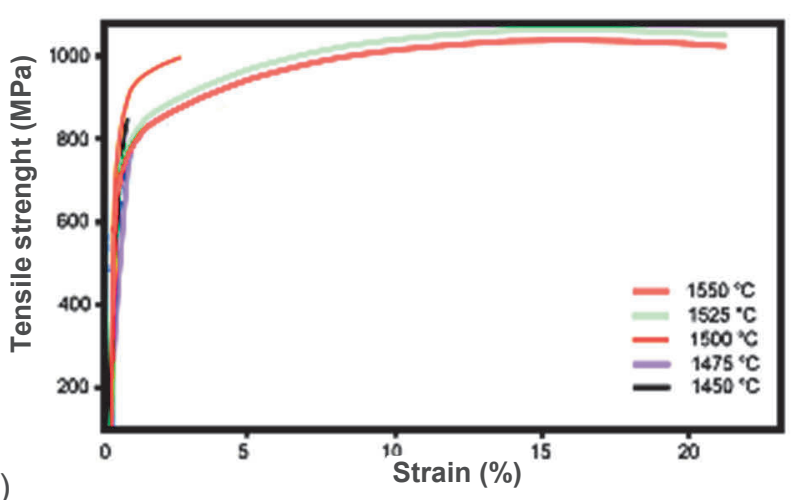

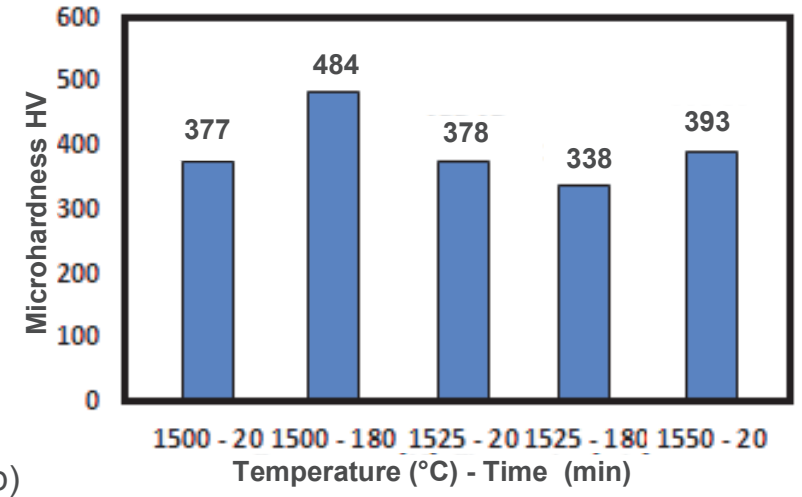

b)

Figure 3 Mechanical properties after sintering (a), microhardness (b)

In order to support the diffusion effect on formation of the desired microstructure, the time period at the maximum temperature was extended up to 180 minutes. However, increase in temperature does not only result in supported diffusion, but also in decrease in both, the tensile strength and hardness [10]. The most favourable mechanical properties were acquired after sintering at the temperature of $1525{ }^{\circ} \mathrm{C}$. The ultimate tensile strength exceeded $1000 \mathrm{MPa}$ while maintaining $22 \%$ ductility, which is very important for further deformation processing (Figure 3a). After finding the critical temperature, finding of the optimum time period at the maximum temperature the most favourable mechanical properties at which can be acquired needed to be performed [11-13]. The microhardness values measured for the individual samples are summarized in Figure 3b. After sintering at $1525{ }^{\circ} \mathrm{C}$ for 20 minutes, the microhardness exceeded the value of $375 \mathrm{HV}$. The results are comparable to findings by Senthilnathan et al. [14]. 
The second part of this study was focused on comparison of the structures after sintering at two different time dwells on the maximum temperature (20 and $180 \mathrm{~min}$ ). The time dwells were chosen according to the demands of the cooperating company (ÚJP Praha, a. s.). The microstructures were investigated by scanning electron microscopy (SEM) in order to compare the final agglomerates sizes. According to the results, increasing the sintering time dwell significantly supports grain growth. Both the temperatures of $1500^{\circ} \mathrm{C}$ and $1525^{\circ} \mathrm{C}$ resulted in bigger agglomerates size after 180 min sintering time dwell.

Structure analyses by SEM showed that the time dwell of 20 was not sufficient for the temperature of $1500^{\circ} \mathrm{C}$ to achieve the desired microstructure (Figure 4a). The longer time dwell at the maximum temperature resulted in the formation of structure consisting of agglomerates and matrix, but the grain growth was critical (Figure 4b). As the optimal sintering conditions were finally designated the temperature of $1525^{\circ} \mathrm{C}$ and 20 min time dwell (Figure 4c). The structure was formed by agglomerates with 20-30 $\mu$ m diameter size, which was in accordance to the demands of the company. The increased time dwell again supported grain growth, as shown in Figure $\mathbf{4 d}$. Figures $\mathbf{4 e}$ and $\mathbf{4 f}$ show the microstructures after sintering at $1550{ }^{\circ} \mathrm{C}$ for $20 \mathrm{~min}$. The structure was fully sintered, but the temperature was unnecessarily high. The grain sizes for the different sintering conditions are compared in Figure 5, which confirmed that the grain size increases with both sintering temperature and time.

a)
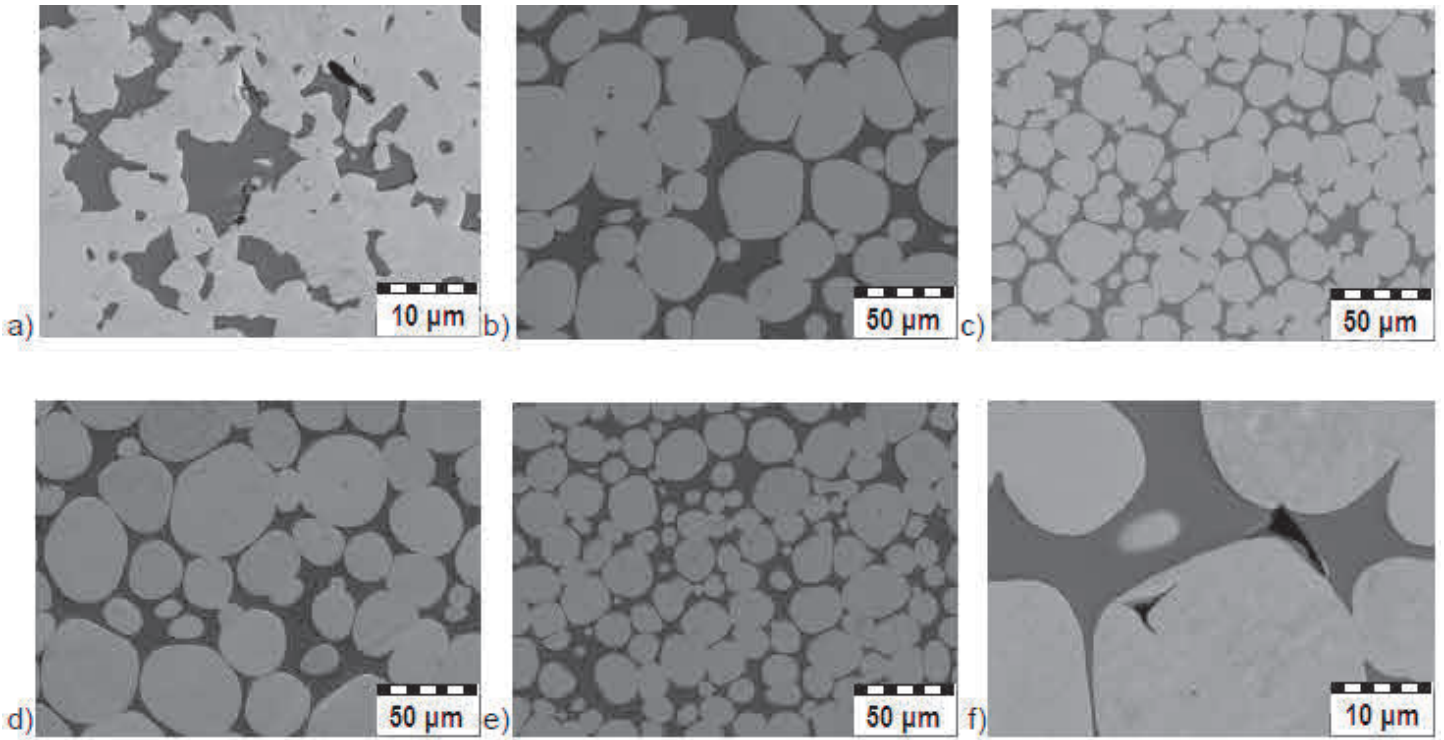

Figure 4 - Structure analyses by scanning microscopy; $1500{ }^{\circ} \mathrm{C}-20 \min (\mathrm{a}), 1500{ }^{\circ} \mathrm{C}-180 \mathrm{~min}(\mathrm{~b})$, $1525^{\circ} \mathrm{C}-20 \min (\mathrm{c}), 1525^{\circ} \mathrm{C}-180 \min (\mathrm{d}), 1550^{\circ} \mathrm{C}-20 \min (\mathrm{e}, \mathrm{f})$

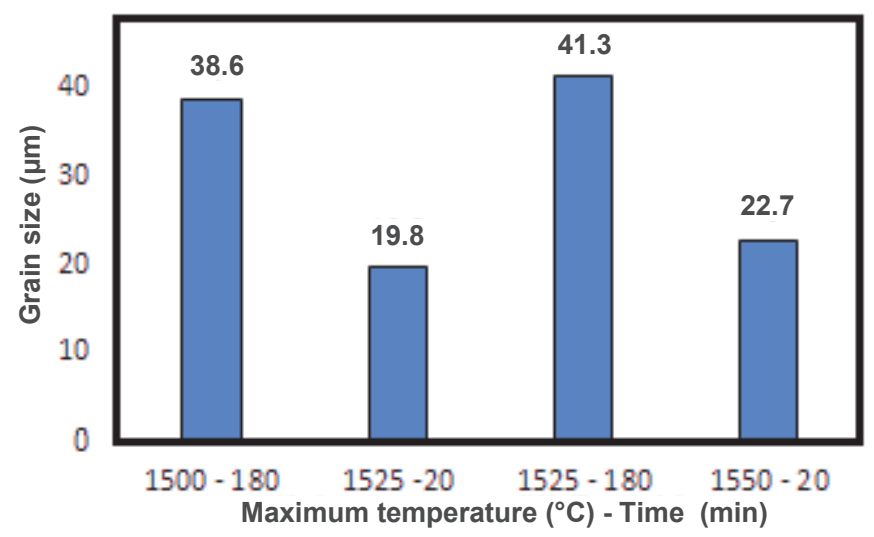

Figure 5 Mean agglomerates size for different sintering conditions 


\section{CONCLUSIONS}

The microstructural and mechanical properties of a tungsten heavy alloy prepared under different sintering conditions were investigated. The critical temperature to acquire the desired microstructure (formation of agglomerates surrounded by matrix) is $1500^{\circ} \mathrm{C}$. Increasing both, the sintering temperature and maximum time dwell, affected greatly the diffusion and grain growth. The sintering conditions were optimized to achieve the structure demands specified by the cooperating company (agglomerates of 20-30 $\mu \mathrm{m}$ ). According to achieved mechanical and microstructural properties, the optimal sintering conditions were selected as $1525{ }^{\circ} \mathrm{C}$ maximum temperature and $20 \mathrm{~min}$ time dwell at the temperature. The microhardness values exceeded 375 $\mathrm{HV}$ for the chosen optimized sintering conditions, while the tensile strength exceeded $1000 \mathrm{MPa}$ at $22 \%$ elongation. Further research will be focused on deformation processing to optimize the mechanical properties of the final product.

\section{REFERENCES}

[1] KOCICH, Radim, KUNČICKÁ, Lenka, DOHNALÍK, Daniel, MACHÁČKOVÁ, Adéla and ŠOFER, Michal. Cold rotary swaging of a tungsten heavy alloy. Numerical and experimental investigations. Int. J. Refract. Met. Hard Mater. 2016. vol. 61, pp. 264-272. Avaliabe from doi:10.1016/j.jigmhm.2016.10.005.

[2] PAPPU, Sridhar, KENNEDY, Christine, MURR, Lawrence, MAGNESS, S. Lee and KAPOOR, Deepak. Microstructure analysis and comparison of tungsten alloy rod and [001] oriented columnar-grained tungsten rod ballistic penetrators. Mater. Sci. Eng. A. 1999. vol. 262, pp. 115-128. Available from: http://dx.doi.org/10.1016/S0921-5093(98)00997-6.

[3] GONG, Xing, FAN, Jinglian and DING, Fei. Tensile mechanical properties and fracture behaviour of tungsten heavy alloys at $25-1100^{\circ} \mathrm{C}$. Mater. Sci. Eng. A. 2015. vol. 646, pp. 315-321. Available from: http://dx.doi.org/10.1016/j.msea.2015.08.079.

[4] KUNČICKÁ, Lenka, KOCICH, Radim, HERVOCHES, Charles and MACHÁČKOVÁ, Adéla. Study of structure and residual stresses in cold rotary swaged tungsten heavy alloy. Materials Science and Engineering A. 2017. vol. 704, pp. 25-31. Available from: https://doi.org/10.1016/j.msea.2017.07.096.

[5] KIRAN, Uddanti Ravi, PANKAL, Ashutosh, SANKARANARAYANA, M., RAO, G.V.S. Nageswara and NANDY, Tapas. Effect of alloying addition and microstructural parameters on mechanical properties of $93 \%$ tungsten heavy alloys. Mater. Sci. Eng. A. 2015. vol. 640, pp. 82-90. Available from: http://dx.doi.org/10.1016/j.msea.2015.05.046.

[6] GERMAN, R.M. and CHURN, K.S. Sintering atmosphere effects on the ductility of W-Ni-Fe heavy metals. Metal Trans A. 1984. vol. 19, no. 4, pp. 747-754. Available from: https://link.springer.com/article/10.1007/BF02644206

[7] CHEN, Chun-Liang and MA, Shih-Hsun. Study on characteristics and sintering behaviour of W-Ni-Co tungsten heavy alloy by a secondary ball milling method. Journal of Alloys and Compounds. 2018. vol. 731, pp. 78-83. Available from: DOI: 10.1016/j.jallcom.2017.09.125

[8] BOSE, A. and GERMAN, R.M. Sintering atmosphere effects on tensile properties of heavy alloys. Metal Trans A. 1988. vol. 19, no. 10, pp. 2467-2476. Available from: https://link.springer.com/article/10.1007/BF02645474

[9] HANSEN, Niels. Hall-Petch relation and boundary strengthening. Scr. Mater. 2004. vol. 51, pp. 801-806. Available from: https://doi.org/10.1016/j.scriptamat.2004.06.002

[10] CHEN, Chun-Liang and MA, Shih-Hsun. Effects of Ni/Co ratio and mechanical alloying on characteristics and sintering behaviour of W-Ni-Co tungsten heavy alloys. Journal of Alloys and Compounds. 2017. vol. 711, pp. 488494. Available from: https://doi.org/10.1016/j.jallcom.2017.04.037.

[11] KIRAN, Ravi, PANCHAL, A., KUMAR, Prem, SANKARANARAYANA, M., RAO, Nageswara and NANDY, T.K. Refractory metal alloying: A new method for improving mechanical properties of tungsten heavy alloys. Journal of Alloys and Compounds. 2017. vol. 709, pp. 609-619. Available from: https://doi.org/10.1016/j.jallcom.2017.03.174. 
[12] PANCHAL, A. and NANDY, T.K. Effect of composition, heat treatment and deformation on mechanical properties of tungsten heavy alloys. Materials Science and Engineering: A. 2018. vol. 733, pp. 374-384. Available from: https://doi.org/10.1016/j.msea.2018.07.070.

[13] KUMARI, Anjali, SANKARANARAYANA, M. and, NANDY, T.K. On structure property correlation in high strength tungsten heavy alloys. International Journal of Refractory Metals and Hard Materials. 2017. vol. 67, pp. 18-31. Available from: https://doi.org/10.1016/j.jirmhm.2017.05.002.

[14] SENTHILNATHAN, N., ANNAMALAI, A. Raja and VENKATACHALAM, G. Synthesis of tungsten through spark plasma and conventional sintering processes. Materials Today: Proceedings. 2018. vol. 5, Issue 2, part 2, pp. 7954-7959. Available from: https://doi.org/10.1016/j.matpr.2017.11.478. 